\title{
O CORPO DO ENSAIO
}

\author{
Paula Padilha \\ ppgpadilha@gmail.com
}

olho muito tempo o corpo de um poema até perder de vista o que não seja corpo e sentir separado dentre os dentes um filete de sangue nas gengivas

Ana Cristina César

Na poesia, o tempo está vinculado apenas ao decorrer do sentido da palavra poética. A linguagem jamais é usada como instrumento de comunicação; ela se volta para a sua irredutível complexidade. A ausência de fundamento da palavra poética é o seu próprio fundamento, uma vez que o instante poético é vertical, descontínuo, com relação ao instante que lhe antecede e também ao que lhe sucede. Por isso cada palavra de um poema é insubstituível e qualquer alteração implica uma mudança completa no poema todo. A poesia é uma experiência com a linguagem, na linguagem, onde palavra e coisa são indistintas. Gostaria aqui de, ao aplicar os mesmos pressupostos da poesia ao ensaio, desenvolver a questãotítulo deste trabalho, seguindo, como linha-mestra, o pensamento do filósofo Walter Benjamin, e de alguns pensadores que se interessaram pelo corpo do ensaio, pela sua forma, como Adorno e Lúkacs. Benjamin não buscava uma totalidade harmoniosa nem no objeto visado nem na própria história. Ele buscava exatamente uma totalidade fissurada, 
composta por fragmentos esquecidos, onde o mundo poderia estar ali contido com todas as suas contradições. E é o ensaio que possibilita, de forma privilegiada, a experiência filosófica proposta.

[...] a 'totalidade' é apenas um clarão, uma intermitência, uma razão jamais explicitada em seu próprio conteúdo. A totalidade que o ensaio atinge não é uma 'explicação do todo', mas apenas o horizonte móvel a que cada objeto é referido, quando a crítica que o descreve ilumina dialeticamente a sua especificidade como relação: a verdade de cada objeto nas suas fronteiras com o outro. (MERQUIOR, 1969, p.116).

A originalidade de Benjamin já se apresentava nos temas escolhidos: sempre exemplos de um problema - um objeto particular - sobre o qual ele queria se deter, num determinado momento, e ao qual a forma do ensaio permite uma nova configuração, e, consequentemente, uma nova interpretação. Na verdade, a relação com o objeto proposta retoma um pensamento por analogia, característico dos intérpretes medievais, contra uma autonomia do método imposta por uma epistemologia moderna baseada na representação. A fronteira erguida pela tradição entre a 'Filosofia Primeira' (ou Metafísica) e outra secundária desaparece. O ensaio introduz o mecanismo alegórico no coração mesmo da reflexão crítica, não se submetendo dessa forma a nenhum tipo de mediação. $\mathrm{O}$ objetivo de Benjamin era o de "conseguir apreender a concretude extrema de uma época, tal qual ela se manifestou aqui ou ali através dos jogos infantis, um edifício, uma situação de vida." (BENJAMIN, 1989, p.15).

O ensaio, porém, não admite que seu âmbito de competência lhe seja prescrito. Em vez de alcançar algo cientificamente ou criar artisticamente alguma coisa, seus esforços ainda espelham a disponibilidade de quem, como uma criança, não tem vergonha de se entusiasmar com o que os outros já fizeram. (ADORNO, 2006, p.16).

É esse entusiasmo que leva Benjamin a se aproximar microscopicamente de cada objeto visado, numa intimidade tal que faz do conhecido algo estranho e por isso mesmo passível de ser criticado. Tratase sempre de um gesto libertador; a crítica "exuma os gestos incompletos que a humanidade deixa inscritos em suas obras.” (MERQUIOR,1969, p.103). Nesse exercício, ele recupera o método alegórico contrapondo a alegoria ao símbolo. No símbolo o significado e o significante coincidem de maneira privilegiada; na alegoria o que se impõe é o afastamento

1 P/ Scholem, Tomo II - 1929, p.15. Todas as traduções foram feitas livremente pelo autor. 
entre significante e significado, a afirmação mesma da verdade como morte da intenção e a compreensão desta sentença está na base da estética benjaminiana. "A alegoria destaca essas dificuldades [somos excessivamente limitados] e está, consequentemente, e de certa maneira, mais próxima da verdade do que a figuração simbólica, que repousa sobre a utopia de uma transparência de sentido." (GAGNEBIN, 1982, p.50).

A alegoria, além de dialética e especulativa, se funda necessariamente num sentido equívoco, uma vez que ela atravessa os extremos sem se preocupar em sintetizá-los. Ela não postula uma unidade do diverso, mas sim uma pluralidade de sentidos evocados no encontro com o objeto na linguagem. "Os impulsos dos autores se extinguem no conteúdo objetivo que capturam." (ADORNO, 2006, p.17). A alegoria é reabilitada por Benjamin que encontra luz exatamente onde a tradição, naquele momento, havia abandonado tal possibilidade. Pensava-se que, pelo fato da alegoria falhar na perfeita tradução do conceito, ela deveria ser descartada, já que a sua natureza arbitrária não seria parelha para a luminosidade do símbolo. Este sim considerado inequívoco.

É no prefácio ao livro sobre o drama barroco alemão (1925) que Benjamin reivindica a forma do ensaio para a filosofia, ao mesmo tempo em que diz que a verdade - questão filosófica por excelência - só pode ser apresentada na linguagem. O conceito de sistema filosófico perde força na medida em que deixa de lado a questão da forma, aspecto incontornável para Benjamin, tão determinante quanto o conteúdo expresso. Tais instâncias nem mesmo existiriam isoladamente. Ele retoma o tratado em contraposição à doutrina, pois eles "podem ser didáticos no tom, mas em sua estrutura interna não têm a validade obrigatória de um ensino, capaz de ser obedecido, como a doutrina, por sua própria autoridade." (BENJAMIN, 1985, p.50). Na verdade, não há nenhuma regra estabelecida a ser seguida baseada num princípio de autoridade que um determinado tipo de 'saber' outorgaria. A única 'autoridade' a ser seguida é aquela imposta pelo próprio pensamento que hesita, retrocede, avança, num movimento intermitente que a escrita filosófica sóbria registra. Esse é o caminho (método) do ensaio. Também é nesse mesmo prefácio que Benjamin retoma $O$ Banquete de Platão para reiterar a importância da beleza, colocando-a no mesmo patamar da verdade e sendo dela, portanto, indissociável, além de reiterar a impossibilidade de um objeto do saber coincidir com a verdade. Em última instância, "a verdade é bela" (BENJAMIN, 1925, p.53), mesmo que ela não passe de uma fulguração. Desde o primeiro momento até o último instante, o pensamento de Benjamin jamais se afastou dessa intuição inicial. A forma transforma o próprio sentido apresentado na escrita. 
E comentários, se necessários que eles se imponham a teus olhos, prejudicarão um pouco a beleza específica do teu escrito. É evidente que esta beleza não é o essencial. Mas nenhum assunto cujo filósofo assuma para si a responsabilidade, a pode negar. Uma análise que sublinhe tal aspecto, omitirá o outro, o fará perder o brilho. E portanto a esperança de um efeito repousa sobre esse estilo... (BENJAMIN, 1989, p.287). ${ }^{2}$

Talvez possamos pensar aqui no papel definitivo que o estilo passa a assumir na filosofia, deixando de ser considerado um mero adereço, e determinando decisivamente a apresentação do pensamento pela escrita. A crítica filosófica, o ensaio, se dirige, em última instância ao estilo. Poderíamos dizer que, para Benjamin, filosofia, crítica, ensaio e estilo se recobrem. A tensão que ele imprime em sua escrita, intercalada por camadas de silêncio e pela expressão mais aguda, revela o testemunho vivo de quem está imerso no objeto visado e ao mesmo tempo se encontra solitário, distante do interlocutor com o qual irá compartilhar suas ideias. Parece que essa distância se faz necessária para que o pensamento ganhe asas num contato o mais íntimo possível com a coisa mesma. Uma intimidade que, entretanto, não perde de vista o afastamento necessário à postura crítica, assumida desde o início. Ele concentra num mesmo gesto clareza e enigma e a sua filosofia se constitui dessa matéria.

"De fato, pode-se ter o sentimento de que a forma do meu trabalho é problemática. Mas não haveria outra para mim nesse caso: pois queria manter as mãos livres; não queria concluir logo." (BENJAMIN, 1989, p.134)3. Manter as mãos livres talvez seja a chave mesma para a compreensão do ensaio, pois significa poder recomeçar a qualquer momento, de novo, mais uma vez; não se submeter à imposição nem de um ponto final nem de um método a priori; não conter o pensamento dentro de um sistema fechado. $\mathrm{O}$ ensaio é a possibilidade de radicalizar o pensamento filosófico na medida em que ele não pode ser medido externamente e o que importa é a relação imediata com o objeto da crítica na linguagem. "O ensaísmo se volta a uma auto-reflexão infinita, a uma sempre aberta revisão de si.” (MERQUIOR, 1969, p.159).

A morte de Benjamin, em 1940, parece ter enterrado com ele as diferenças tão debatidas com Adorno através das extensas cartas trocadas

2 P/ Rang, F.C., Tomo I - 1923, p.287

3 P/ Werner Kraft, Tomo II - 1934, p.134 
pelos dois amigos nos anos trinta. As duras críticas feitas pelo segundo exatamente à forma dos seus ensaios e a reivindicação de uma mediação que explicitasse com mais clareza a teoria apresentada desaparecem, dando lugar a um pensamento que se fundamenta em conceitos centrais da própria filosofia de Benjamin. Adorno acata o pedido de Benjamin, expresso em seu último dia de vida, e zela pela obra do amigo morto, não só tentando editá-la, como dando cursos sobre a sua filosofia. Os pontos de contato a partir de então se intensificam e em muitos momentos Adorno parece estar apenas corroborando um pensamento tão singular e declara: "o que Benjamin dizia e escrevia soava como se brotasse do mistério, mas recebia seu poder da evidência.” (citado por ADORNO, In: SCHOLEM, 2004, p.19)

"O ensaio como forma" de Adorno, incluído no livro Notas de literatura I e publicado em 1958, é exemplar ao revelar uma afinação intelectual incontestável. Nesse belo trabalho, Adorno apresenta a sua 'própria' ideia de ensaio e defende ser ele uma forma na qual "seus conceitos não são construídos a partir de um princípio primeiro, nem convergem para um fim último." Ele faz uma crítica ao espírito científico da academia que, segundo ele, tem alergia contra as formas, sendo, portanto obtuso e dogmático.

O ensaio, em contrapartida, incorpora o impulso anti-sistemático em seu próprio modo de proceder, introduzindo sem cerimônias e 'imediatamente' os conceitos, tal como eles se apresentam. Estes só se tornam mais precisos por meio das relações que engendram entre si. [...] Na verdade, todos os conceitos já estão implicitamente concretizados pela linguagem em que se encontram. O ensaio parte dessas significações e, por ser ele próprio essencialmente linguagem, leva-as adiante. (ADORNO, 2006, p.29).

Uma vez que a reflexão acontece sempre na linguagem, na sua relação com os conceitos que já estão nela, a forma do ensaio se ancora num procedimento que não pretende determinar um sentido estrito sob cada conceito, nem delimitar arbitrariamente o objeto visado atrás de certezas definitivas. Tal atitude certamente induz à possibilidade da errância, vista com muito bons olhos, tanto por Benjamin, quanto por Adorno. O que interessa no ensaio é o movimento do pensamento, sempre intermitente. "O modo como o ensaio se apropria dos conceitos seria, antes, comparável ao comportamento de alguém que, em terra estrangeira, é obrigado a falar a língua do país, em vez de ficar balbuciando a partir de regras que se aprendem na escola." (ADORNO, 2006, p.30). Talvez o ensaio não seja tão reconhecido pela ciência como uma forma privilegiada à expressão do pensamento filosófico pelo desconcerto que 
ele provoca ao não oferecer de antemão garantia alguma. O que há é o próprio caminho aberto pela escrita. Um caminho constituído por fragmentos e onde a totalidade só pode ser encontrada nessa instância mínima da realidade, suspensa no instante mesmo em que se apresenta. O ensaio busca uma objetivação do espírito, entretanto tal objetivação não pode visar uma consolidação da teoria, mas sim deve concentrar-se na forma de apresentação dessa teoria que não possui independência alguma para além dela.

O ensaio tem a ver, todavia, com os pontos cegos de seus objetos. Ele quer desencavar, com os conceitos, aquilo que não cabe em conceitos, ou aquilo que, através das contradições em que os conceitos se enredam, acaba revelando que a rede de objetividade desses conceitos é meramente um arranjo subjetivo. (ADORNO, 2006, p.44).

O princípio do sistema, ao contrário, é tratar o objeto à exaustão de maneira que nada permaneça oculto ou não-dito. Este seria o trabalho dos conceitos que precisam ser bem definidos para garantir o sentido preciso que cabe a eles representar seguindo um método já posto. $\mathrm{O}$ ensaio não compactua dessa crença e persegue a marcha do próprio pensamento que avança sempre para além dos muros erguidos pelos conceitos que ele mesmo engendra. "Essa configuração é um campo de forças, assim como cada formação do espírito, sob o olhar do ensaio, deve se transformar em um campo de forças." (ADORNO, 2006, p.31).

Ao deixar de lado o método cuja pretensão central é não deixar escapar nada, o ensaio se permite ser uma construção inacabada, constituída por fragmentos, como a própria realidade. A teoria da linguagem de Benjamin propõe uma verdade ancorada no sensível, na escrita, e um respeito à impossibilidade de se determinar os contornos dessa verdade de forma definitiva. Há sempre um novo olhar, há sempre um novo contexto, há sempre um novo leitor, haverá, portanto, sempre uma nova face dessa verdade a ser apresentada. Adorno corrobora este pensamento e contrapõe o ensaio ao método científico: "Enquanto ciência do espírito, a ciência deixa de cumprir aquilo que promete ao espírito: iluminar suas obras de dentro." (ADORNO, 2006, p.24).

Benjamin reunia características inigualáveis para a escrita ensaística, além da sua conhecida capacidade de concentração e de um perfeccionismoímpar, ele possuía "uma rara mistura de extrema abstração, plenitude sensual e plasticidade na exposição, [...] Sem abandonar a 
profundidade da análise, sua linguagem se amolda prodigiosamente ao objeto." (SCHOLEM, 2004, p.26). Porque a própria verdade não existe fora da linguagem e está dessa forma sujeita ao seu ritmo interno, como ele mesmo já havia declarado a Hofmannsthal numa carta de 1924:

\begin{abstract}
É para mim muito importante que o senhor releve com tanta nitidez a convicção que me guia em meus ensaios literários e, se compreendo bem, que o senhor compartilha. Esta convicção de que toda verdade tem a sua morada, seu palácio ancestral na língua, que este palácio é feito dos mais antigos logoi e que, face a uma verdade assim fundada, as visadas das ciências particulares permanecem subalternas tanto quanto, nômades num certo sentido, elas se contentam com soluções aleatórias aos problemas que a linguagem coloca, cativas de uma concepção que, concebendo a linguagem como um simples signo, afetam a sua terminologia de uma irresponsável arbitrariedade. (BENJAMIN, 1989, p.301). ${ }^{4}$
\end{abstract}

A potência do pensamento de Benjamin consiste justamente em sua imensa capacidade de iluminar ao mesmo tempo pólos opostos, aquilo que se apresentava como radicalmente contrário. Ele não queria perder o precioso de nenhum dos extremos e todo o seu esforço se concentra nessa tarefa crítica. Tal esforço tem a ver, não só com o mecanismo alegórico que torna desperto o que permanecia adormecido sob um resíduo da história, mas também diz respeito à relação do presente com o passado distante, expresso na imagem dialética que produz um sentido num salto abrupto para fora da linha horizontal do tempo. O eixo da sua dialética imóvel se manifesta num gesto tenaz de tornar o sagrado profano e vice-versa e por isso encontramos reiteradamente em seus textos termos característicos da mística judaica, como salvação, redenção, messianismo. Benjamin opera uma espécie de torção na carga que cada palavra carreia ao retirar o tom elevado inerente e trazê-la para 'dentro do tempo', trazê-la para a história, onde o sujeito, como um indivíduo detentor de uma intuição intelectual, desaparece.

Seu ensaísmo consiste em tratar os textos profanos como se se tratassem de textos sagrados. Ele não se agarrou de modo nenhum mais aos resíduos teológicos, não mais do que à tarefa de trazer de volta o mundo profano a um sentido transcendente, à maneira dos socialistas religiosos. Ao contrário, é somente a partir de uma profanação radical, sem reservas, que ele esperava uma chance de salvação para a herança teológica que esses últimos haviam dilapidado. A chave do enigma se perdeu. (ADORNO, 1999, p.19).

4 P/ Hofmannsthal, Tomo I - 1924, p.301 
"Seu método microscópico e fragmentário jamais assimilou a ideia da mediação universal que, em Hegel como em Marx, institui a totalidade." (ADORNO, 1999, p.22). Essa frase de Adorno escrita em 1950, dez anos após a morte do amigo, poderia constar numa das cartasresposta de Benjamin nos anos trinta e deixa claro como o ponto central das intermináveis discussões ocorridas até a morte de Benjamin, sobre a questão da 'falta de mediação' sempre criticada nos ensaios que ele enviava ao Instituto para Pesquisas Sociais, do qual Adorno fazia parte, foi finalmente compreendido ou, pelo menos, respeitado. Parece que a imperturbável fidelidade com que Benjamin sustentou suas ideias centrais e a sua defesa de uma dialética materialista, mais preocupada em relacionar o objeto com a história do que em interpretar cada fenômeno isoladamente, encontram finalmente o seu lugar na filosofia. Na verdade, a sua grande preocupação com relação à história era com a sua transmissão, uma vez que há um caráter fugaz constitutivo da vida que não pode ser agarrado por uma tradição engessada, embora ele tenha sempre um olhar respeitoso e terno em direção ao passado.

Para Scholem, o grande amigo e interlocutor da vida inteira, que ele conheceu na universidade em Berlim e que se mudou em 1923 para Jerusalém, onde se tornou o maior especialista da mística judaica, a força do pensamento de Benjamin provinha da sua metafísica da linguagem, e toda vez que este se aproximava da dialética materialista, acabava confundindo religião com política. A dialética de Benjamin não é materialista, para Scholem ele apenas jogaria com as ambiguidades e os fenômenos de interferência do método materialista. Numa carta de 1931, Benjamin responde de forma irônica: "Ignoro como o materialismo dialético pode fazer do materialismo vulgar uma rede tão apertada que captura pássaros raros como você e eu." (BENJAMIN, 1989, p.63)5. O comunismo para ele está longe de ser um credo; ele considera haver uma certa inconsistência no movimento e uma total falta de liberdade. Tratava-se apenas de algumas experiências feitas em seu pensamento e em sua vida. Jamais se filiou ao partido, mesmo sob forte influência do amigo Brecht e de Asja Lacis, uma russa por quem se encantou e que o moveu a viajar até Moscou.

Eledefendiaaideia dequeo choquepromovidopela própria montagem do texto, pela sua forma de apresentação, provocava o surgimento de significações, contra um método exaustivo de interpretação. A questão não é perseguir um ponto de vista externo ao objeto, nem tentar uma 
unidade que não seja desde sempre fraturada: "O ensaio continua sendo o que foi desde o início, a forma crítica par excellence; mais precisamente, enquanto crítica imanente de configurações espirituais." (ADORNO, 2006, p.38). Antes mesmo de escrever sobre o cinema como a arte fragmentada por excelência, Benjamin já havia relacionado o método filosófico ao mosaico, que não perde sua majestade mesmo sendo por natureza composto por fragmentos. Assim como o tratado, o mosaico também é característico da época medieval e o fato dele se constituir de uma reunião de elementos heterogêneos se compara ao próprio movimento do pensamento, "cujo fôlego infatigável é a mais autêntica forma de ser da contemplação.” (BENJAMIN, 1985, p.50). O mesmo se dá com a montagem do ensaio; cada epígrafe, cada citação, a pontuação, a mancha gráfica no papel, todos os aparentes pequenos detalhes, têm o poder de tornar o texto mais ou menos denso; mais ou menos claro; mais ou menos expressivo. "A relação entre o trabalho microscópico e a grandeza do todo plástico e intelectual demonstra que o conteúdo de verdade só pode ser captado pela mais exata das imersões nos pormenores do conteúdo material." (BENJAMIN, 1985, p.51).

\footnotetext{
Método deste trabalho: montagem literária. Não tenho nada a dizer. Somente a mostrar. Não surrupiarei coisas valiosas, nem me apropriarei de formulações espirituosas. Porém, os farrapos, os resíduos: não quero inventariá-los, e sim fazer-lhes justiça da única maneira possível: utilizando-os. (BENJAMIN, 2006, p.502).
}

Segundo Adorno, uma das características marcantes de Benjamin era a sua arte para a fórmula instantânea e definitiva. Ele tinha por princípio não excluir nada à reflexão; tudo lhe despertava interesse. Nada devia ser posto de lado, muito menos os pensamentos furtivos que parecem não ter nada a ver com o conteúdo da reflexão principal. Cada anotação, cada pedaço de papel esquecido no bolso do paletó, cada conversa, cada leitura, tem uma função determinante sobre o trabalho em andamento. Essa atitude tinha a ver com "o compartimento do espírito reservado geralmente à arte, mas que, transposto para o plano teórico, se emancipa e acede a uma incomparável dignidade: a promessa de felicidade." (ADORNO, 1999, p.11). A certeza de que alguma nova experiência surgiria, sob um resíduo do passado, o movia a não rejeitar nenhum evento que surgisse enquanto escrevia. Especialmente na escrita nada devia ser descartado. Um caco da história poderia ser a chave para a compreensão 
de uma dimensão mais alargada da experiência histórico-filosófica, entre o mito e a reconciliação.

Benjamin reivindica para a sua escrita a força salvadora que ele atribuía à categoria judaica do estudo, ou seja, a força da reviravolta que transforma o que existe em escrita. Ao associar linguagem e conhecimento com experiência, ele alarga o âmbito da sua teoria, permitindo, por exemplo, que se possa experienciar Deus, embora não possamos conhecê-lo. "Ao contato íntimo dos objetos, em sua afinidade com o que é dado, seu pensamento tinha sempre, apesar de toda a sua distância e sua acuidade, um aspecto singularmente inconsciente, naïf se quisermos." (ADORNO, 1999, p.22). Quando Rang encaminha o ensaio de Benjamin sobre As afinidades eletivas de Goethe a Hofmannsthal em novembro de 1923 para ser publicado na Neue Deutche Beiträge, num lugar de honra, este responde:

Tudo que posso dizer é que ele marcou época em minha vida interior [...]. Para não falar apenas da sua forma exterior, me parece maravilhosa a grande beleza da escrita numa apreensão tão exemplar do mistério; esta beleza cuja fonte está num pensamento plenamente seguro de si e puro, do qual conheço poucos exemplos. (citado por WITTE, 1988, p.77).

A leitura de Georg Lukács também marcou época na vida interior de Benjamin que chega a dizer que a sua teoria do conhecimento e a dele são muito parecidas. O ensaio A propósito da essência e da forma do ensaio de Lukács de 1910, escrito como uma carta ao amigo Leo Popper, exerce uma influência marcante na própria reflexão de Benjamin sobre a questão da forma do ensaio. Adorno também leu o mesmo ensaio e esta leitura transparece no seu $O$ ensaio como forma, já citado.

A carta-ensaio escrita por Lukács levanta uma pergunta que o tomava naquele momento: diante de vários ensaios escritos que ele gostaria de reunir num livro, ele indaga se haveria ou não uma unidade nova que valesse o empreendimento. A questão colocada é se há ou não alguma unidade entre os ensaios e, em caso positivo, qual seria ela? Não se trata de restringir o problema a um caso particular, mas sim de transportá-lo para um âmbito mais geral e tentar entender a própria constituição do ensaio e a possível unidade de um livro de ensaios. O que o ensaio, "que possui uma forma que o distingue com um rigor definitivo de uma lei de todas as outras formas de arte" (LUKÁCS, 1974, p.13) quer dizer? Lukács está mais preocupado em capturar a singularidade do ensaio, tentando 
discernir o que o difere de outras formas, sem, no entanto, deixar de caracterizá-lo como uma forma de arte.

Trata-se de saber como os escritos realmente grandes pertencentes a esta categoria são formados, e em que medida esta forma que é a sua é autônoma. Como o modo de aproximação e a forma que damos retiram a obra do domínio das ciências e a coloca ao lado da arte sem, entretanto, apagar suas fronteiras, dando-lhe a força de aceder a uma reordenação inteligível da vida e a mantém, entretanto, afastada da definitiva perfeição de gelo própria à filosofia. (LUKÁCS, 1974, p.12).

"Nas ciências os conteúdos agem sobre nós, na arte as formas." (LUKÁCS, 1974, p.14). Esse é o elo que une as estéticas de Benjamin, de Adorno, e do jovem Lukács, empenhados em compreender a natureza própria do ensaio e convencidos de que ele é uma forma autônoma. Quando Lukács se refere $a$ vida e a vida - a vida vivida e a vida lembrada - distinguindo portanto duas realidades psíquicas contidas em qualquer experiência humana que só podem acontecer em momentos distintos, ele quer demarcar a diferença entre tais experiências para a seguir privilegiar o ensaio como o único lugar onde elas podem se dar simultaneamente. Quando Adorno cita Bense ele também quer ressaltar o valor da experiência crítica do ensaio:

O ensaio é a forma da categoria crítica de nosso espírito. Pois quem critica precisa necessariamente experimentar, precisa criar condições sob as quais um objeto pode tornar-se novamente visível, de um modo diferente do que é pensado por um autor; e sobretudo é preciso pôr à prova e experimentar os pontos fracos do objeto; exatamente este é o sentido das sutis variações experimentadas pelo objeto nas mãos de seu crítico. (citado por ADORNO, 2006, p.38).

A função da crítica é fazer o sangue circular novamente na obra da qual ela parte, após imobilizá-la, e a sua tarefa consiste em reordenar uma forma dada num novo contexto histórico. Se a filosofia é sempre crítica, a reflexão sobre a própria linguagem é matéria constituinte de qualquer ensaio, uma vez que o objeto e a sua forma de apresentação são inseparáveis. O movimento do pensamento caminha na direção dos limites da escrita, da relação fundamental entre pensamento filosófico e linguagem.

Nesse sentido, segundo Benjamin, a filosofia consistiria na sempre renovada tentativa de nomear a essência histórica e linguística do pensamento, uma tentativa de auto-reflexão que realça seus limites temporais e linguísticos, sua finitude e sua mediação pelas línguas, auto-reflexão que se opõe, portanto, 
à pretensão de perenidade e de autonomia do sistema. (GAGNEBIN, 2007, p.89).

Em Kant, a crítica se situa entre a razão e a sensibilidade; para os românticos ela se transforma num gênero teórico entre a literatura e a filosofia - o que faz com que a crítica de arte ganhe fôlego a partir deles, pela sua importância decisiva para a sobrevida de uma obra. O caráter subjetivo visado, tanto por Kant quanto pelos românticos, dá lugar, nesses últimos, a uma crítica imanente, uma vez que ela deixa de ser um julgamento exterior à obra e passa a se constituir como uma autoreflexão que se desenvolve e se dissolve nela mesma. Para Benjamin a própria filosofia é crítica e a crítica é sempre filosófica. A auto-reflexão acontece no ensaio, na linguagem, e tem sempre um caráter objetivo que a força a voltar minuciosamente às próprias coisas.

\begin{abstract}
A dificuldade intrínseca dessa forma de apresentação mostra que ela é, por natureza, uma forma de prosa. [...] na escrita é preciso, com cada sentença, parar e recomeçar. A apresentação contemplativa é semelhante à escrita. Seu objetivo não é nem arrebatar o leitor, nem entusiasmá-lo. Ela só está segura de si mesma quando o força a deter-se, periodicamente, para consagrar-se à reflexão. (BENJAMIN, 1985, p.51).
\end{abstract}

\title{
O CORPO-A-CORPO DA IDEIA
}

Para Lukács, há uma fronteira clara entre o ensaio, a arte e a ciência. Ambos se tocam, em certa medida, estando o ensaio distante tanto da ciência quanto da filosofia. Para ele, em 1910, a filosofia se caracterizava por uma perfeição de gelo. Já Benjamin aproxima filosofia e ensaio de tal forma que eles se tornam indiscerníveis, uma vez que é justamente o ensaio que permite que o sangue circule novamente na obra da qual ele parte. Esta seria a função central da filosofia, portanto, da crítica, matéria esta constituinte da própria obra. Há, para Benjamin, em cada obra um pedido de salvação que só o crítico pode realizar. E como se pode salvar uma obra, uma ruína, ou um caco da história? Escrevendo sobre eles.

Embora compreendendo a questão que movia Lukács, gostaria aqui de me alinhar com o pensamento benjaminiano e defender a tese de que o corpo-a-corpo da ideia se dá na linguagem e que o ensaio, por permitir uma liberdade que a própria linguagem reivindica, é o lugar onde a filosofia se apresenta da maneira mais expressiva, uma vez que a forma assume um papel decisivo, como na poesia. É esse papel decisivo que constitui o estilo, que determina o sentido do que se quer dizer. É claro 
que esse querer dizer carreia consigo uma certa presunção, pois nunca se sabe bem aonde se vai chegar na escrita, e, como diz Benjamin: "a verdade é a morte da intenção." Essa é a magia da linguagem, que jamais pode ser medida de fora. Há um movimento objetivo no interior na linguagem que não pode ser controlado por um sujeito consciente e toda graça consiste em se deixar levar por esse movimento intermitente, que caminha muito próximo ao próprio pulso do pensamento. Se pudéssemos determinar um aspecto que atravessa todo pensamento de Benjamin um pensamento que não sofre grandes modificações do início ao fim, embora ganhe novas camadas reflexivas - este seria a reivindicação de uma temporalidade intensiva à filosofia, sugerindo que ela se aproxime da arte e se afaste da temporalidade extensiva característica da ciência.

Após a morte de Benjamin, Adorno se volta para o que havia em comum entre eles, não só corroborando suas ideias centrais, como as levando adiante nos cursos que passa a ministrar na universidade de Frankfurt. Ao contrário de Benjamin, Adorno obteve êxito em sua carreira acadêmica, tendo publicado uma obra extensa e tendo sido reconhecido ainda em vida pelo seu trabalho.

A tarefa da crítica refundada como gênero por Benjamin, como ele havia antecipado a Scholem numa carta de $1930^{6}$, passa a ser a de produzir uma verdade filosófica e não a de determinar juízos. "Mas, ao mesmo tempo e num único e mesmo gesto, ela faz com que se escutem novos cantos, ela anuncia uma nova maneira de cantar a imanência pura." (PROUST, 1998, p.47). A verdade que há na obra - e que se dá a ver pelas mãos do filósofo que, ao incendiar o teor material, libera o teor de verdade inscrito na obra -, no ensaio, é assim desencantada e apresentada ao mesmo tempo. A morte da intenção é a condição mesma da sobrevida da obra, uma vez que a reflexão crítica parte do encontro da obra com o tempo presente, e se abre às infinitas possibilidades de configuração da ideia na linguagem. A característica inacabada do ensaio que se funda na história é a forma eleita por Benjamin para sustentar um tipo de pensamento que não pretende capturar uma verdade unívoca e definitiva.

6 "Le but que je m'avais [!] proposé n'est pas encore pleinement réalisé, mais, enfin, j'y touche d'assez près. C'est d'être considéré comme le premier critique de la littérature allemande. La difficultè c'est que, depuis plus de cinquante ans, la critique littéraire en Allemagne n'est plus considérée comme un genre sérieux. Se faire une situation dans la critique, cela, au fond, veut dire: la recrée comme genre." (BENJAMIN, 1979, p. 28). 


\section{REFERÊNCIAS BIBLIOGRÁFICAS}

BENJAMIN, Walter. Passagens. Org. BOLLE, Willi. Trad. ARON, Irene e MOURÃO, Cleonice P. B. Belo Horizonte, Ed. UFMG, 2006.

BENJAMIN, Walter. Paris, Capital du XIXe Siècle, le Livre des Passages. Trad: J.Lacoste. Paris, Cerf, 2002.

. Correspondance. Trad: G.Petitdemange. Paris, Aubier-Montaigne, 1989.

. Origem do drama barroco alemão. Trad: S.P.Rouanet. São Paulo, Brasiliense, 1985.

ADORNO, Theodor. Notas de literatura I. São Paulo, Ed. 34, 2006.

. Sur Walter Benjamin. Frankfurt am Main, Allia, 1999.

GAGNEBIN, J.M. Walter Benjamin, os cacos da história. São Paulo, Brasiliense, 1982.

LUKÁCS, Georg. "A propos de l'essence et de la forme de l'essai: une lettre à Leo Popper." In: L'Ame et les formes. Trad: Haarscher.G., Paris, Gallimard, 1974.

MERQUIOR, José Guilherme. Arte e Sociedade em Marcuse, Adorno e Benjamin. Rio de Janeiro, Tempo Brasileiro, 1969.

PROUST, Françoise. "La Tâche du Critique". In: Walter Benjamin: Ästhetik und Geschichtsphilosophie, Gérard Raulet e Uwe Steiner (Org.), Bern, Peter Lang, 1998.

SCHOLEM, Gershom. Los nombres secretos de Walter Benjamin. Trad: R. Ibarlucía \& M. García-Baró. Madrid, Minima Trotta, 2004.

SELIGMANN-SILVA, Márcio. Leituras de Walter Benjamin. São Paulo. Annablume. 2007.

WITTE, Bernd. Walter Benjamin, Une biographie. Trad: A. Bernold. Paris, Éditions du Cerf, 1988. 